\title{
Chinese Community and Social Network in the Marketing of Agricultural Products: A Phenomenological Study
}

\author{
Novel Lyndon 1
}

Lim Jie Wei²

\begin{abstract}
Mohd. Nor Shahizan Ali ${ }^{3}$
${ }^{1}$ Associate Professor at School of Social Development and Environmental Studies, Faculty of Social Sciences and Humanities, Universiti Kebangsaan Malaysia, Bangi, UKM 43600, Selangor D. E., Malaysia, novellyndon@yahoo.com ${ }^{2}$ Research Assistant at School of Social Development and Environmental Studies, Faculty of Social Sciences and Humanities, Universiti Kebangsaan Malaysia, Bangi, UKM 43600, Selangor D. E., Malaysia, ending89@gmail.com 3Senior Lecturer, Faculty of Social Sciences and Humanities, Universiti Kebangsaan Malaysia; shahizan@ukm.edu.my
\end{abstract}

Doi:10.5901/mjss.2015.v6n4s3p117

\section{Abstract}

Social network is a step or an effort to remain competitive with other manufacturers in the agricultural activities. Therefore, the main objective of this study is to examine the types of social networks used by the Chinese farmers in the marketing and finding the best price for their agricultural products. The idealist ontology and epistemology interpretivism were used in this study. Data was collected using the in-depth interviews and non-participation observation. Purposive and snowball sampling techniques were used in selecting the informants in this study. The total number of informants in the study is determined based on the saturation data. The validity and reliability of the data were determined using the member checked approach. The study found that the type of social network used by the Chinese farmers in marketing of their agricultural products can be divided into eight types, namely friends, family, social environment, dialects, values, experience, aid from the state and the wholesalers. These eight types of social networks have helped the Chinese farmers to remain competitive with the leading producers of vegetables and other fruits although there is lack of support from the government agencies in terms capital and marketing their product compared to their other Bumiputera counterparts.

Keywords: phenomenology, guanxi, social network, marketing, agriculture, Chinese farmers

\section{Introduction}

Malaysian total population in 2010 was estimated at 29.337 million comprising of 91.9 per cent citizen and 8.1 per cent non-citizen (see Figure 1). Of that amount, $67.4 \%$ are Bumiputera, whereby $56.4 \%$ are Malays and $11 \%$ are other Bumiputera. Other Bumiputera are made up of the Orang Asli, Siamese, Eurasian, Baba and Nyonya (Peranakan) and other Bumiputera minorities in Peninsular Malaysia (Malaysia, 2010). While in Sabah, it is known as the Bumiputera Sabah which has 33 native groups and Sarawak has 27 native groups. Approximately $24.6 \%$ of the Malaysian population are Chinese and 7.3\% comprised of Indians and both are the minority race groups in Malaysia (Malaysia, 2010).

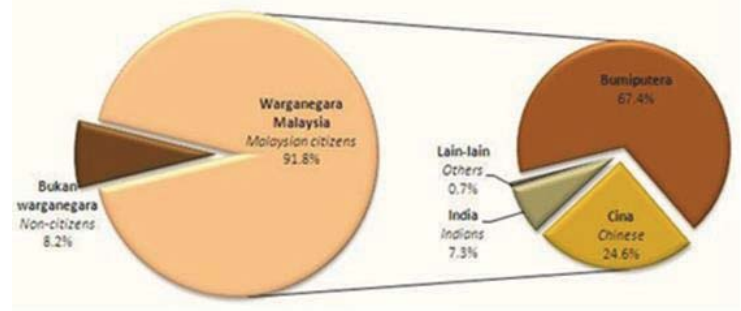

Figure 1. Distribution percentage of the Malaysian population based on race (2010)

Source: Malaysia, 2010 
The Chinese ethnic of Malaysia consist of Foochow, Hainanese, Henghua, Hokkien, Cantonese, Hakka, Teochew and others (Pack, 2008). Although the Chinese has been accepted as a citizen of Malaysia after the country gained independence in 1957, the racial relationship between them and the Bumiputeras are still at the moderate level (Shamsul, 2004; Ong, 2007). Feelings of insecurity, discrimination, misgivings and suspicions between them and other ethnic groups still exist and are reflected in their faces (Pack, 2008; Super et al., 2013; Ong, 2007). On the basis of the Chinese community social cohesion and sense of belonging and Guanxi among them is crucial in determining the survival of their lives, particularly in terms of economic, social and political (Song, 2004; Pack, 2008; Lim, 2001). This situation coupled with the New Economic Policy (NEP) which was implemented in 1971 by the Malaysian government is not so favorable to them and more focused to develop the Bumiputera economy mainly the Malays in agriculture, industry, business, marketing, services and others ( Madeline, 2004; Super et al., 2013; Ong, 2007). This situation led to the social network or guanxi being seen as a philosophy or approach that is very important to the Chinese farmers in marketing the agricultural products, especially in an unhelpful economy (Lim, 2001; Chen, 1995), lack of marketing assistance from the government agencies (Qinxian, 2012; Pack, 2008), increase in competition (Super et al., 2013), more agricultural output but low demand (Serrat, 2008), agricultural output are less known and volatilities in the market prices of agricultural products (Qinxian, 2012; Serrat, 2008; Ishfaq et al., 2013).

Evaluated in passing, the social network is a network of information sharing between the individuals who provide enough value to justify the retention of the relationship between the two parties based on mutual goals or benefits (Ritzer, 2000; Qinxian, 2012). The Chinese philosophers also see social network as Guanxi that is an individual's network ties or 'special relationship' or 'profit-based network between two or three individuals' (Davies et al., 1995; Chen, 1995). Guanxi is developed with intelligence, creativity and equipped with flexibility (Kao, 1993; Quinn, 2003). The guangxi concept is embedded in the philosophy of Confucius through the theory of social hierarchy that defines the Chinese moral code outlining five relationships between government and subject, father and son, husband and wife, relatives and lastly friends (Qinxian, 2012; Kim Nam, 1998; Chen, 1995). The importance of guanxi in the business and agricultural marketing sector in the Chinese community has been discussed by many scholars (Redding, 1993; Pack, 2008; Wong, 2007; Yang, 2011). The Sociologists then see this aspect as a network of contacts in the community which is the network of individuals and families, between individuals and communities and between individuals and society based on the equality of desires and actions. This network is often associated with the social interaction either symbolic or face to face due to the development of society from people who are Gemeinschaft in nature that is people who share common values and beliefs to the Gesellschaft society that is a separated modern society having weak individuals' relationship (Ritzer, 2000; Mazzucato, 1997; Triandis, 1995). The economists see social network as a network resulting from the social interactions between individuals and communities and this social interactions are created due to the social capital and the market.

Accordingly, the network of individuals in the society is important because it will contribute to the cooperation between the two parties concerned, namely between the producers and the buyers and the relationship between the producers and the buyers are mutually complementary (Qinxian, 2012). Cooperation here means a process in which two or more people or organizations working together towards a common goal as a result of knowledge sharing (Kao, 1993; Shortall, 2004) and learning (Qinxian, 2012). Ritzer (2000) then see this collaboration in three forms, namely micro level (starting with individuals or small groups of individuals based on social context and social relations based on snowballing), meso (population size between micro and macro) and macro (tracking the results of interactions such as the economic resource transfer interactions or the transfer of resources over a large population). The three forms of cooperations will further produce a consensus to cooperate with each other, or vice versa (Shortall, 2004). Therefore, most of the economic scholars see the concept of social network as an interaction to gain profit and expand the market. The wider the size of an individual's social network, the bigger and wider the market and more complex is the relationship (Ritzer, 2000; Qinxian, 2012; Kao, 1993). Therefore, the main objective of this study was to examine the type of social networks used by the Chinese farmers in marketing their agricultural products and the reasons they choose the type of social network.

\section{The Guanxi Concept and Marketing of Agricultural Products of the Chinese Community}

Social network in the Chinese community context is commonly known as guanxi (Chen et al., 2004; Pack, 2008; Ishfaq et al., 2013). Guanxi can be referred to as a personal social relations among the Chinese and guanxi brings confidence and security among each other. Accordingly, guanxi is very important in the marketing of agricultural products and dominates the market. This is because guanxi refers to the relationship between individual with two or three other individuals (Glenn Hammond, 2004). Basically, guanxi refers to the sibling relationship, kinship relationship, friends and they share common 
environment, experiences and goals (Fan, 2002; Yum, 1998; Yang, 2011). The guanxi relationship is a dynamic process and it is in the daily interactions by every member of the society. This relationship is established based on the motive and kindness between the two parties (Gold et al., 2002) consolidating and expanding the relationship between people, especially in the context of business and marketing of agricultural and manufactured Chinese products (Pekk, 2008). Guanxi was developed from various factors and aspects such as dialect, ethnicity, locality, social environment, familial and kinship (Heywood, 2008; Fiona, 20013; Qianxin, 2012). Guanxi in Chinese communities is shaped by the Confucian teachings (Kao, 1993; Wong, 2007). Confucian teachings emphasize the importance of relationship between human, especially between family and relatives in the daily lives. In Confucian, there are five types of most basic social relations. Among them are the relationship of a father and a child (cheng), the government's relationship with the governed, between husband and wife (pieh), brother-sister relationship (hsu) and friendship (hsin) (Quinn, 2003; Wong, 2007). In guanxi, the Chinese will use la guanxi (developing the social network or relationship) with another person intentionally to achieve a mutually agreed objective (King, 1991). The Chinese are very concerned about 'personal trust' or hsin and yi in the Confucian concept in conducting business activities and marketing of the agricultural and manufactured products (Brown, 1996). Personal trust is developed from guanxi. Briefly, guanxi is defined as a relationship or a mechanism of social relationship that can help individuals achieve personal objectives, family or business (Glenn Hammond, 2004).

In addition, the Chinese guanxi is an important element in determining the success of businesses and marketing of the agricultural products among the Chinese people, especially in times when they are in a marginalized state, discriminated against by the system and the government (Fan, 2002; Yum, 1998). The personal relationship (guanxi) is the most beneficial relationship between two or more individuals who provide ongoing assistance either in terms of advice, financial assistance, moral support, and others. In other words, when their ethnic or dialect sell the agricultural products or doing business, they should help by buying them. Qianxin (2012) sees this situation likened to a clump of bamboo that moves to the rhythm of the wind. Envy and jealousy is not in their dictionary of life. In fact, with the existence of 'guanxi', one can access the main source of information, resources, productions and marketing networks including smoothing the transportation, product marketing, smoothing payment collection and building the reputation and image of the firms (Davies et al., 1995). On this basis, Yang (2011) saw 'guanxi' as a social interaction between two or more individuals based on the specific need that will eventually result in a bilateral or social networking in business and marketing. In short, it refers to an interpersonal relationship, something personal and built on specific criterias.

\section{Research Methodology}

\subsection{Description of the study area}

Pahang is the largest state in Peninsular Malaysia with a total population estimated at 1,440,741 and bordering the state of Kelantan, Perak, Selangor and Negeri Sembilan in the west, Johor in the southern and East Terengganu (Malaysia, 2010). In terms of distribution by ethnicity, the Malays are the largest ethnic group with a total percentage of $76.82 \%$ $(1,010,249)$, Chinese, $17.7 \%$ (222.390), Indian, 4.98\% (60.718) and other ethnic groups such as Orang Asli and others, $0.5 \%(5,909)$. Pahang state has 11 districts comprising of Bentong, Bera, Cameron Highlands, Jerantut, Kuantan, Lipis, Maran, Pekan, Raub, Rompin and Temerloh (see figure 2). This study was conducted in the District of Raub, Pahang. Raub district is located about $110 \mathrm{~km}$ from Kuala Lumpur, the capital of Malaysia, and $265 \mathrm{~km}$ from the city of Kuantan, the state capital. Raub District is the oldest district in Pahang and famous for gold mining and durian. Raub District consists of 7 sub-districts or areas of Batu Talam, Sega, Semantan Ulu, Dong, Ulu Dong, Gali and Tras and the total area of Raub District is $2,271 \mathrm{~km} 2$. Raub District is located in the west of Pahang and in between the two Titiwangsa Range and Mount Benom. Raub District main economic activity is agriculture. The main cash crops in Raub District is rubber, oil palm, cocoa, local fruits and vegetables. The location studied is included in Figure 2

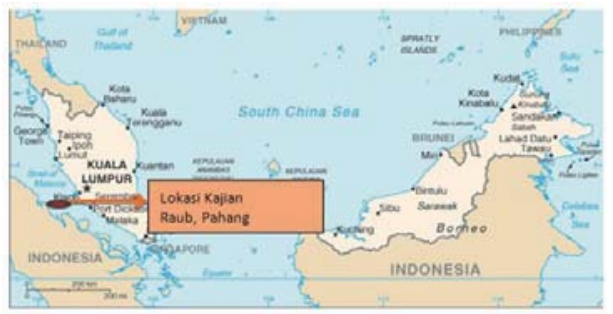

Figure 2. Research location 


\subsection{Research Method}

This study used a phenomenological approach based on the idealist ontology and epistemology constructionism. The main focus in the phenomenological approach is to define and describe the experience and knowledge of the social actors on a concept that was based on their world view and not the views and perceptions of the researchers. The interviews between the researchers and the informants were focused on the type of social networks and social networks sizes in the marketing of their agricultural products. Most of the interviews were conducted for a period of two to three hours and there are also some of the interviews conducted that took too long. The research data were collected using the non-probability sampling method that is purposive sampling and snowball sampling. A total of 20 Chinese farmers were selected in this study based on the predetermined criteria. Among them are; the farmers must have experience in the cultivation of vegetables and fruits for more than 10 years and his income should depend entirely on the agricultural products. Data were collected using in-depth interviews and the questions guide was developed to assist the interviewing processes. Size of the samples was achieved through continuous support towards the measure or criterion of theoretical saturation. According to Blaikie (2000) and Neuman (2006), the theoretical saturation occurred or happen when there are no new themes or categories that appear and there is no relevant data that can be discussed or acted against the existing categories. All interviews will be transcribed and formatted for inclusion in the Nvivo database and used to create the categories and to index the data.

\section{The Study Result and Discussion}

Majority of the informants in this study stated that the social network or guanxi is a very important aspect in marketing their agricultural products, especially when production exceeds demand and for perishable crops like fruits and vegetables. The type of social network or guanxie that is most important to them in search of the agricultural markets are through friends, family relations, social environment and dialects (see Figure 3). Without social network or guanxie it is likely that they will suffer losses and move to other sectors as the main economic resources. This is because it is very difficult to remain competitive with the private companies that have huge capitals, social networks and market size of the global nature which are also involved in planting the same crops. This situation, coupled with the rising cost of fertilizers, labor costs, costs of pesticides, transportation costs, limited market and the elimination of government subsidies led to profits sometimes just enough to be used as capital. Accordingly, the role of guanxi is very important for their survival through macro markets and across the Raub district border, particularly in the city of Kuantan which has high population density. With a vast market and network of contacts through guanxie has made them remain choosing farming as the main source of their economies and thus be able to compete with the private companies that also participate in the agricultural activities, particularly for crops such as vegetables. Thus, for the majority of the informants in this study, social networks or guanxi is the savior of their lives. Followings are descriptions of informants on the matter.

\subsection{Friends (huo ban) (伙伴)}

Majority of the informants in this study stated that the type of network through friends or huo ban is the most important social network type to them due to its existing common or personal compatibility between them to achieve the targets or goals that have been set. This relationship is usually interpersonal or bilateral. This method or technique was named by scholars such as Fan (2002) and Yang (2011), Qianxian (2012) and Wong (2007) as the snowball method because the individual will introduce individuals known to him to other individuals, and other individuals will introduce them to another friend and this process will then continue to form a larger social network. Great social network will further help them find customers and making profits based on a win-win situation. Normally, when their colleagues managed to introduce their products to other people and that person purchased his agricultural products, then their friends will be given discounts or rebates from the original price. Followings are some of the informents' statements on the matter. 


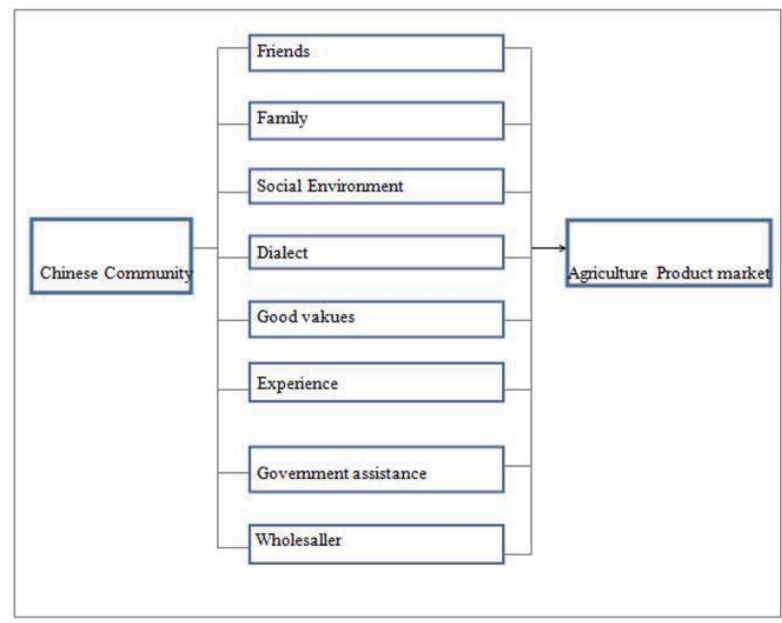

Figure 3. Types of the Chinese community marketing social network of the agricultural produce

"Every day, I would go to the coffee shop not to chat but to find friends. The more people I know, the easier for me to sell my chilies. Almost all my chillies agricultural products are using this kind of network with the colleagues in seeking for the customers. Sometimes I did not know them, but they say they know me through their friends. If they help me find my customers, I will give them discounts. I must thank my colleagues. Sometimes I treat them with drinks when my chilies sales increased." (R1).

'My strength here is that I know a lot of people in this area. The more contacts, the easier to do business selling vegetables and fruits. They have already trusted me and I will give a lot of discounts if they introduce my vegetables to others. My clients are not only from this area but up to Kuantan town "(R2).

"Friends are important if you want to do business, like selling goods and want to sell vegetables. They have already trusted us and know that we will not cheat them. Trust has already existed. If there are no friends, who will buy our goods. A lot of competitions. Must be good in creating networks. If not how to live. Expect the government to help, they do not exist" (R4).

\subsection{Family (jia ting) (家庭)}

Majority of the informants in this study also stated that the family relationship is the most important aspect and most often used to market their agricultural products. According to them, family or 'jia ting' is a person who has blood, marriage or adoption relationship. Family is also a sharing unit between individuals who respond and depend on each other and have the same purpose theme, promised to share resources and place to stay for a long term. Almost all of the informants in this study stated that the type of family that exists within them are the 'conjugal' family. The 'conjugal' family refers to a family who has close ties with other relatives and can seek help from relatives when needed. Almost all informants in this study stated that the family relationship is the biggest customers of their agricultural products. This is due to the average buyer of their vegetable products are their family members, who are near or far. Majority of the informants in this study stated that a family member refers to the immediate family members and much like siblings, relatives, kinsfolk, relatives and family from the wife's or husband's side or other siblings. This matter coincides with the comments expressed by the previous researchers like Heywood (2008) and Cheng et al. (2006) who stated that the family relationship is the most important social network or guanxi to the Chinese community because the Chinese community believe their family members more than others. This concept is called xin ren. This is because when they get into trouble, the first person to be contacted for help and personal protection is the family members.

\subsection{Social environment (she hui huan jing) (社会环境)}

The social environment or she hui huan jing meant by majority of the informants in this study refers to the elements of 
humanity such as peer influence (tong ban), influence of the society, personal interaction or a one-way or two-way communications and interactions through communication media such as face book and mobile phone with the outside community or other ethnic groups. The influence of social environment will actually help them identify the strengths and weaknesses and threats in the marketing of agricultural products. The threat may be internal or external. This coincides with the comments given by Shortall (2004) which states that the she hui huan jing concept assist farmers in identifying weaknesses and strengths of the social networks constructed by them. Besides that, it helps in identifying the opportunities that exist outside their area. Therefore, the average informants interviewed agreed that a good social environment helps them in terms of giving the latest information and the knowledge on the market, the current price of plants and customers to the Chinese farmers in marketing their agriculture products. This matter were stated by six informants namely R8, R10, R14, R15, R16 and R17. Followings are their statements on the matter.

"Meet up with members of the community in search of ideas and market opportunities. The more we interact with the villagers, the more we know what kind of vegetables are their favourite "(R8).

"I often interact with the Malays in my area to get some views and advice from them, especially in terms of current prices and market. It is because they have close political ties with the government "(R10).

"The business opportunities are very good if we are courteous and good with people here. I do not totally accept information conveyed by the ruling government. Information communicated mainly on the price of agricultural products and agricultural aid are more to political interests without considering the actual realities "(R14).

"I like hanging out with people here, especially my peers who have different backgrounds and different cultures to get some ideas and knowledge on how to expand the market. I have many Malay and Indian friends. Through them I know the strengths and weaknesses of the market as compared to the conventional alternative media "(R15).

"The influence of the social environment is important to reflect ourself, our current position in the market. We will know when the price of the vegetables rise, and when it goes down and when demand rises. If for example, during the festive seasons we will make more profit because of the high demand" (R16).

"Face to face interaction is important in seeking for customers. The more we are faced with the customers, then we will have our regular customers. a good social environment is very important in raising the spirit to do business" (R17).

\subsection{Dialect (yu yan) (语言)}

The dialect factor (yu yuan) used by individuals who do business with them will also determine the social network in marketing of the agricultural products. Majority of the informants in this study stated that they would prefer to establish a marketing network with the same individual or clients having the same dialect as theirs compared to other Chinese dialects. This is because they are the minority in the country and solidarity-based dialect in building a social network business is very important in determining the survival of their lives. Furthermore, the network base on dialect will help them share the same sense of belonging, sharing the education and training of the same religion and have come to understand their culture, morality and attitudes. Therefore, it is not surprising when majority of the buyers, social network friends and the regular customers of their agricultural products are made up of the Chinese with the Cantonese dialect. This is in line with the statement made by Emile Durkheim in Lukes (1973), a sociologist who states that in a traditional society, homogenous and small-scale, their solidarity and social interactions are dependent upon dialect, language, family members and friendship factors.

\subsection{Good values (mei de)(美德)}

The social networks in the Chinese community is still influenced by the values found in the Confucian teachings. Among the most favored in the Chinese community is hsin and yi. Majority of the informants in this study consider hsin as the key element in creating social network. In the selling and purchasing of agricultural products, most of the farmers and the business partners in the social networks already have credit facilities or deposit money to trade by mutual agreement which has been formally signed. The use of credit facilities is very dependent upon the trust between farmers and members of their social network. This has been stated by several informants as R3, R1, R2, R15, R17 and R20. 
"If I find that there are unfair things like the existence of fraud, I would dismiss him as a social network" (R1).

"There should be honesty and win-win situation in the marketing of agricultural products" (R2).

"There must be money savings or credit facilities in doing business with the buyer.There is no concept of debt here" (R15).

"I am very concerned about the Confucian teachings in the marketing of agricultural products. The Hsin and yi concept must be used among friends in the business social network" R17).

"The profit will not last if fraud and back stabbing are practice in doing business. The most important thing is small profits but many customers"(R20).

\subsection{Experience (jin yan) (经验)}

Only a handful of informants in this study stated that experience is the most important aspect in building the social network. Experience here refers to the individual's experience in mastering or understanding the roles, functions and responsibilities of the farmers, customers, purchasers and also as traders. In addition, it also includes skills in predicting the prices and the level of acceptance of a product, and help farmers and marketing network to plan their activities more effectively. Success can never be achieved through a simple and concise way. When an individual has mastered the all the experiences, then it is easy for the individual to create social networks with others. This is due to the establishment of the reliability and validity elements of the individual's achievement in agricultural marketing activities. However, informants in this study did not specify the duration of an individual's experience needed in forming the experience social network.

This was stated by three informants.

"I do not prescribe the duration of an individual's experience in the marketing of agricultural products. The most important thing is that these individuals know the responsibilities and hardships as farmers" (R7).

'Experience is very important to me in assisting the social network. The social network built must have experience among members. Then they will know their roles and not only based on profit" (R10).

"When there is experience, people will believe in you. Then people will buy our agricultural products. It is difficult at first and things become easier later. The basis of the social network is to begin from the bottom that is experiencing the difficulties first" (R20).

\subsection{Government's assistance (zheng fu yuan zhu) (政府援助)}

Majority of the informants in this study stated that they did not received marketing assistance from the government, especially from the agency responsible that is the Federal Agricultural Marketing Authority (FAMA). Only one of the informants received marketing assistance. However, it is very limited and restricted. Majority of the informants stated that it is difficult to get the marketing assistance of the agricultural products due to the highly complex and troublesome bureaucratic, inability to speak Malay fluently, often fail when making the application, lack of information and government policies are not transparent in distributing the aid. Even so, they are able to have the marketing social network with the government through the help of the Malays by making them their business partners. The good social networkings with the Malays has enable them to become major manufacturers and distributors of the agricultural products of vegetables and fruits at the farmers markets and night markets. Here are a few of the informants' responses on the matter.

"It is not easy to penetrate the farmers' markets and the night markets if there is no social networkings with the Malays. The Malays can easily obtained assistance from the government as compared to the Chinese" (R14).

'It's difficult to apply for the marketing assistance from the government agencies. There are many forms to be filled up. Not necessarily can get"(R16).

"The applications for marketing assistance of the agricultural product for small-scale farmers like me are always difficult. Must be fluent in Malay when dealing with the agency"(R17). 


\subsection{Wholesaler (zong jie shang) (中介商)}

Only a small number of the informants in this study stated that they are using wholesalers as a network in marketing their agricultural products. However, the use of wholesalers is their last option. This is because the profits are usually small and does not commensurate with the time spent by them in the farm. The wholesalers consist of the night market traders, weekly markets, morning markets, shopping centers and farmers' markets. Usage of the wholesalers has to be done as a result of fatigue after a long day in the farm, lack of time due to the perishable crops and the amount of production that exceeds demand. Followings are the statements issued by a small number of the informants on the matter: "My last choice in marketing of agricultural products is via wholesalers. Although the margin is small it should be done
to avoid losses resulting from the vegetables and fruits that are easily perishable due to late trading" (R7).

"My agricultural product wholesalers consists of the night market, morning market and the farmers' markets traders. It is easier and faster. This is to avoid the agricultural product from perishable"(R9).

"I have to use the wholesalers due to fatigue after a long day in the farm. I have no choice. Moreover, there are times that the vegetables harvested are more than the demand" (R12)

"I lack the time to sell the agricultural products. I work in the farm from morning till evening. The wholesalers that I selected are those who can buy the vegetables and fruits in bulk. This saves my time and energy"(R15).

\section{Conclusion}

The study found that the concept of social network (guanxi) used by the Chinese farmers in this study are more focus on the appropriateness, the wants and the needs of the Chinese farmers themselves in an effort to ensure that they remain as the major producer of the agricultural products in the local market and also as a weapon to face competition from the large companies involved in the same sector. Therefore, it is not surprising when the types of social networks used are still in the family and micro context that is between colleagues, friends, colleagues in the same area, and kinsfolk and the next of kin. This coincided with the statement made by sociologist like Qianxian (2012) and Yang (2011), stating that the social network or guanxi refers to a personal relationship that transcends kinship and friendship. Social network in the Chinese community context can be mobilized and used to achieve the desired results even though sometimes it is beyond the capacity of an individual (Quinn, 2003; Brown, 1996). In short, the social network that is understood by the Chinese community is more utilatarian, reciprocity, personal, long-term and sustainable base on the shin and yi (Chen, 1995; Fan, 2002).

\section{Acknowledgement}

The researchers would like to thank the University Kebangsaan Malaysia through the provision of Young Researchers Fellowship Scheme 2013 and Research University Grant (Project Code: GUP-2014-074) which enables smooth implementations of this research.which enables the study to be carried out smoothly and perfectly.

\section{References}

Blaikie N. (2000). Designing social research. Polity Press, Cambridge.

Brown RA. (1996). Chinese business enterprise critical perspective on business and management II. Routledge, London.

Fiona. (2003). Confucius and the Chinese way of doing business. University of Sydney Press, Australia.

Chen M. (1995). Asian management systems. Routledge, London.

Chen CC, Xin K. (2004). Guanxi practices and trust in management: A procedural justice perspective. Organization Science 15 (2), 200209.

Chou LF, Cheng BS, Huang MP, Cheng HY. (2006). Guanxi network and members' effectiveness in chinese work teams: Mediating effect of trust network. Asian Journal of Social Psychology 9, 79-95.

Davies H, Leung T, Luk S, Wong YH. (1995). The benefits of Guanxi: The value of relationships in developing the Chinese market. Industrial Marketing Management 24, 207-214.

Fan Y. (2002). Guanxi consequences: Personal gains at social cost. Journal of Business Ethics 38 (4), 371-380

Gold T, Guthrie D, Wank D. (2002). Social connections in China; Institutions, culture and the changing nature of Guanxi. Cambridge University Press, United Kingdom.

Hammond SC, Glenn LM. (2004). The ancient practice of Chinese social networking: Guanxi and social network theory. 6 (1-2) 2005. 
24-3 [cited 30/3/2012]. Available from: http://www.emergentpublications.com/Eco/eco_other/issue_6_1-2_6_ac.pdf.

Heywood EP. (2008). Market research in China: The impact of the guanxi on business. Unpublished Master Project School for International Studies, University of Simon Fraser.

Ishfaq A, Wan KWI, Salmiah MA, Muhammad MN. (2013). A social exchange perspective of the individual guanxi network: Evidence from Malaysian-Chinese employees. Chinese Management Studies 7 (1), 127-140.

Kao J. (1993). The Worldwide Web of Chinese business. Harvard Business Review (March-April), 24-36.

Kim J, Nam S. (1998). The concept and dynamics of face: Implications for organizational behavior in Asia. Organization Science 9 (4), $522-534$.

King AY. (1991). Kuan-hsi and network building a sociological interpretation. Social Science 120 (11), 9-26.

Lim L. (2001). Work-related values of Malays and Chinese Malaysians. International Journal of Cross-cultural Management 1 (2), 229 246.

Lukes S. (1973). Emile Durkheim: His life and work. Allen Lane, London.

Madeline B. (2004). Towards the national vision policy: Review of the economic policy and new development policy among the bumiputera communities in Sarawak. Journal of Malaysian Studies 21 (1 \& 2), 211-256.

Malaysia. (2010). The Ninth Malaysian Plan, 2006-2010. Percetakan Nasional Malaysia Berhad.

Mazzucato V. (1997). Indigenous economies: Bridging the gap between economics and antropology. Indigenous Knowledge and Development Monitor 5 (1), 3-6.

Neuman W L. (2006). Social research methods: Qualitative and quantitative approaches, 6th edn. Allyn\& Bacon, Boston.

Ong PL. (2007). Identity matters: Ethnic salienceand perceptions in Malaysia. In: Abdul Rahman Embong (ed) Rethinking ethnicity and nation-building: Malaysia, Sri Langka \& Fiji in comparative perspectives, pp. 216-234. Malaysian Social Science Association, Kuala Lumpur.

Pek C K .(2008). Insight of Chinese economics culture in Malaysia. International Journal of Business and Management September 3 (9), 65-73.

Qinxian G. (2012). Leadership in Malaysia: Managerial and strategic implications of Chinese face (mianzi), relation ties (guanxi) and human affection (renqing). Paper presented at XIX Biennial Conference of the European Association of Chinese Studies (EACS), Paris, September $4^{\text {th }}-8^{\text {th }}$.

Redding SG, Ng M. (1982). The role of face in the organizational perceptions of Chinese managers. Organizational Studies 3, 204 209.

Ritzer G. (2000). Classical sociological theory, $3^{\text {rd }}$ edn. McGraw-Hill Companies, United States of America.

Shamsul AB. (2004). Texts and collectivememories: The construction of "Chinese andChineseness" from the perspective of a Malay. In: Leo Suryadinata (ed) Ethnic relations and nation-building in Southeast Asia, pp. 109-144. ISEAS, Singapore.

Shortall. (2004). Social or economic goals, civic inclusion or exclusion? An analysis of rural development theory and practice. Sociological Ruralis 44 (1), 109-123.

Serrat O. (2008). Social networks analysis [cited 23/2/2012]. Available from: http://www.adb.org/sites/default/files/pub/2009/socialnetworks-analysis.pdf.

Song HS. (2004). Success stories: Entrepreneurship at its best. Malaysian Institute of Management (MIM), Kuala Lumpur.

Triandis HC (1995) Individualism and collectivism. West view Press, Boulder, Company, New York.

Wong ML .(2007). Guanxi and its role in business. Chinese Management Studies 1 (4), 257-276.

Yang F .(2011). The important of guanxi to multinational companies in China. Asian Social Science 7 (7).

Yum JO. (1988). The impact of confucianism on interpersonal relationships and communication patterns in East Asia. Communication Monographs 55, 374-388. 